\title{
Surface Features of Code-switching in 'The Nigerian Online Community' Page on Facebook
}

\begin{abstract}
Existing studies on code-switching have mainly been carried out among English/Chinese bilinguals. Studies on English/Yoruba/Pidgin English bilinguals with emphasis on code-mixing and code-switching on the Internet have been grossly insufficient. Therefore, this study reveals the surface features of code-switching among Yoruba/English/Pidgin English bilinguals in the Nigerian Online Community on Facebook. For theoretical framework, we relied on insights from Halliday's (1994) functional theory of language. Five types of surface features were identified: simplified lexicon and sentences, non-adherence to the use of tones/diacritics, inconsistencies of spellings and words, unnecessary lengthening of letters, and tolerance of surface errors. The study has revealed the distinctive features of code-switching in the Nigerian Online Community page on Facebook. These linguistic features have thrown more light on the characteristics of the language use on the Facebook forum and how the posters use the codes in their speech repertoire to achieve this.
\end{abstract}

Keywords: Bilingualism Code-Switching, Facebook, Online Community, Surface features.

\section{Introduction}

Nigerians already had their indigenous languages before the advent of the English language in Nigeria. In this situation, English came in contact with the indigenous languages such as Yoruba, Hausa and Igbo, etc.

Many activities resulted in the implantation of the English language in Nigeria. One of them was the boom in the slave trade that spanned both the pre-colonial and colonial periods. Also, the monopoly of trade enjoyed by England along the West African coast set the stage for the easy penetration and the use of English along the West African coast and its land, including Nigeria. This contact situation between Portuguese, English and indigenous Nigerian languages resulted in of Pidgin (Awonusi, 2004) One fact that is generally accepted about Pidgin languages all over the world is that they arise from contact situations. In particular, such contact has no common means of communication. Pidgins have thus often been called contact, trade, or auxiliary languages (Elugbe \& Omamor, 1991).

Wardhaugh (1998) sees Pidgin as a language with no native speaker: it is no one's first language but a contact language. He further explains that Pidgin is a product of a multilingual situation in which those who wish to communicate must find or improvise a simple language system that will enable them to do so. He says further that the process of pidginization probably requires a situation that involves at least three or more languages one of which is clearly the dominant over and above the others.

Finch (2000) asserts that Pidgin is an auxiliary language which arises to fulfill certain limited communication needs among people who have no common language. Trade was (and is still) a factor bringing people with different linguistic backgrounds together. Evidently, therefore, trade language provides the basis for the development of Pidgin. It evolves when people with an extended contact need some means of verbal communication, perhaps for trade. Nigerian Pidgin would then be traced to the advent of Europeans to Africa for among other things trade purposes, slave trade being cardinal (Holm, 1988). Finney (2004) posits that Pidgin is a version of English that is augmented by features of Nigerian languages.

If culture and values of the people are inherent in the language they speak, then language is culture and none can be separated from each other (Edward Sapir, 1929). So, when two languages are in contact, this results in bilingualism. In a bilingual situation, the phenomena of 
code-mixing and code-switching are inherent in the repertoire of bilingual speakers. A society does not exist in isolation; rather it exists alongside the other cultures. This is a situation of English, Yoruba and Pidgin in Nigeria.

Akindele \& Adegbite (2005) hold the opinion that each of the various languages has distinct phonological, lexical, grammatical and discourse rules. Each language, therefore, forms a code of communication in the community or individual who uses it. Examples of bilingual speech communities are Canada where English and French are considered very important to the life of the people; Nigeria, where several bilingual speech communities exist, e.g. Hausa/Kanuri bilingual community, and in Britain where some communities are bilingual, e.g., Wales where they speak Welsh and English. Examples of individual bilingualism can be observed in a country like Canada where members of that speech community are made to speak both French and English in order to be able to function within that society. In Nigeria, there are bilinguals who speak only Yoruba and English, Hausa and English, Igbo and English, Efik and English, English and Pidgin, and the like (Akindele \& Adegbite). This study investigates the features of Nigerian bilinguals' use of code-switching on the Internet using the Nigerian Online Community page on Facebook.

One of the consequences of bilingualism is codeswitching (CS). There is no way two or more languages can exist in the repertoire of an individual without codeswitching or code mixing whether consciously or subconsciously. Code-switching can be described as a means of communication which involves a speaker alternating between one language and the other in communicating events. In other words, someone who codeswitches uses two languages or dialects interchangeably in a single communication. This switching can be interlingual or intralingual (Akindele \& Adegbite, 2005). A communication which may involve a native tongue and a foreign language or two foreign languages or two dialects of a language can be initiated with one of the two languages and be concluded in the other e.g., starting a discussion in Igbo and concluding in English (Akindele \& Adegbite, 2005).

Myers-Scotton (1979) sees code-switching as a choice in determining the linguistic choices used in a conversation where the rewards and costs for using either of the languages were weighed by the switcher to achieve a particular outcome. This was further represented in her Markedness Model based on the social motivation of codeswitching. The model considers on the notion of codeswitching as language choices made by speakers and it is seen as either an unmarked or marked language choice in different speech situations. Code-switching is deemed as an unmarked or safe choice when it is more or less expected in a particular type of interaction that is being determined by factors other than the conversation content such as social and situational settings.

This study is located within the ambit of Sociolinguistics, which studies the relationship between and the society that uses it. Society and language are like Siamese twins that can never be separated. Society does not exist in a vacuum; rather, it exists with the people and the language they speak. The objective of the present study is to investigate the use of code-switching, which is a major feature of bilingualism in a society. The study pays particular attention to code-switching among bilingual users of English, Yoruba and Pidgin in order to discover the various surface features of code-switching in internet chatting, especially the Facebook forum.

Most of the studies on code-switching are on faceto-face or written communication while the switching of codes on the Internet is not well researched despite the fact that code-switching online had attracted the attention of linguists from as early as the mid-1990s (Georgakopoulou 1997). This motivates the researcher to contribute his own quota to this aspect of Internet chatting using a Facebook forum to investigate the surface features of code-switching among English, Yoruba and Pidgin bilinguals on the Internet. In other words, this study fills this gap and explores this aspect of Internet communication that has not yet been fully exploited. English and Yoruba languages are selected because the phenomena of code-mixing and codeswitching are fully demonstrated by the posters using these languages on the forums.

\section{Theoretical Background}

The Systemic Functional Grammar (SFG) employed as a theoretical framework for this study was developed by M. A. K Halliday, who built this conception of language on the ideas of his tutor, J. R Firth. Halliday's Systemic Functional Grammar (SFG) considers language as a system network of interlocking options and a semiotic system, from which each choice is made against the backdrop of other available alternatives that could have been chosen but were not, and each selection serves as an entry condition leading to others in an intricate closed network. Thus, the process of making meanings is a process of choosing from the total linguistic system (Halliday, 1994). Gotzche (2009) opines that SFG considers language to be a resource that is fundamentally shaped by the uses that people make of it. Therefore it tries to explain the forms of language in relation to the meanings that they express.

SFG identifies three types of meaning are called metafunctions. Ideational meaning is concerned with the way we encode our experience of the world, including our inner world of consciousness. Its lexico - grammatical realization is the transitivity system, which according to Eggins (1994:12), refers to the "semantic processes expressed by clauses containing the process realised by the verb, the participants in the process realised by noun phrases, and the circumstances associated with the process expressed by adverbial and prepositional groups". Textual meaning refers to the way words are put together to form a text or the way words are related to what was said before and the context. It is realised by the thematic and information structures through the organisation of elements in a clause, and by patterns of cohesion through the use of pronouns, 
repetition, ellipsis and so forth. Interpersonal meaning refers to meaning about social relations and social roles, attitudes and beliefs expressed between participants in the exchange of goods, services or information. This metafunction is realized through patterns of mood and modality.

Halliday's functional theory of language suits this study because it exposes the social functions performed by posters on FACEBOOK forums. It also shows how the users of the forums mix and switch from one language to another to exhibit their communicative intentions. Some linguists have claimed that code-mixing is a category of code-switching. The major difference is that code-switching is inter-sentential while code-mixing is intra-sentential

\section{Review of Literature}

Many scholars have worked on code-mixing and codeswitching on computer-mediated discourse. CardenasClaros and Isharyanti (2009) examine the occurrence of code-switching and code-mixing in a chartroom based environment. The participants were from an Indonesian background and six participants were from a Latin American background representing five nations: Colombia, Chile, Uruguay, Mexico and Argentina. The researchers found out that Indonesian participants shifted code more often than Spanish speaking participants, while Spanish speakers switched code 116 times, Indonesians switched code 174 times. Also, their data indicate that most code alternation was triggered when participants used the function of the language 'conforming'. The study is relevant to this present study because it shows the functional use of language which is one of the claims of Halliday's Functional Theory of Language.

Huang (2004) investigates code choice and language use in the emails written by eight Chinese and English speakers in Taiwan. Having analysed 223 emails including questionnaire and interviews, the study reveals that participants used three modes of conversation on Internet discourse. The first mode is Chinese/English bilingual mode, the second one is Chinese monolingual mode and the last one is English monolingual mode. The study found out that participants in email writing used English monolingual mode to show online identity. In other words, the mode is a mark of identity. Also, the participants used Chinese monolingual in the expressions of their personal thought. The study further reveals that Chinese mode is not favoured in email writing as it is in verbal communication. Huang's work is a bit relevant to this study. This is because, his study shows how bilingual speakers use different languages to suit different purposes online. It also shows how bilinguals code-mix and code-switch among languages to show identity among the posters.

Androutsopoulous (2001) investigates the switching from national language to English in media discourse by German youths. The data were drawn from sample of magazine and web texts. The former covered four typical genres: editorials, news, interviews, and record reviews. This amounts to 24,000 words. The latter consisted of 300 entries from five guest books with a total of 17,500 words. The researcher's findings support two conclusions with regard to language contact in modern media discourse. One, the findings suggest that the use of English as a lingua franca in media discourse is diversified in accordance with particular audience communities. The impressive amount of vernacular English used by young German writers indicates the importance of multiple paths of linguistic transmission in globalised media landscapes. Two, the findings suggest that the Internet is an important site for the diversification of media discourse. More precisely, certain social uses of the Internet, such as the web communities create new literacy spaces that allow for more instances of code-switching and code-mixing than is the case in traditional media formats. The study suggests that codeswitching is a natural phenomenon among bilinguals. In a situation whereby two or more languages exist in the repertoire of a bilingual, there is the tendency for codemixing and code-switching. This practice is predominant in a computer-mediated discourse, which appears to be a great avenue to do so. The study is significant to this present study because it shows how social uses of the Internet have brought about code alternation in the language of its users. Huang (2009) investigate how Chinese-English bilinguals in Taiwan use languages in computer-mediated communication via Bulletin Board System (BBS) and email. The researcher's main data were emails collected from a social network and postings collected from two BBS websites. By examining the patterns of language choice and language use in the data, the study reveals that there are levels of code-switching. One is between languages and the other between writing systems. In the case of the former, three patterns of code-switching are identified: switching between Mandarin and Taiwanese, switching between Mandarin and English and switching among Mandarin, Taiwanese and English. In the latter, three patterns of codeswitching are also identified: code-switching between Standard Written Chinese (SWC) and Zhuyin, switching of codes between SWC and the English alphabet, and switching between SWC, Zhuyin and the English alphabet. The study concludes that code-switching is found to be a common phenomenon on asynchronous CMC, where it fosters multilingualism and multi-orthography.

Androutsopoulos (2011) discusses code-switching in a wide range of computer-mediated modes and social settings, including texting among South African young people, chatting among second-generation Indians, emails among Egyptian professionals, forum discussions among Persian expatriates, and fan fiction by Finnish bloggers. The study presents the number of cases where bilingual practices are not verbatim reproductions of face-to-face interaction patterns but, judging from ethnographic and linguistic evidence, specific to online communication, the study discovers that rather than examining code-switching online in terms of its authenticity or equivalence to offline speech, a more productive question to pursue is how codeswitching is used as a resource, under the specific conditions of communication offered by digital media. The research 
work further suggests that even though pragmatic force depends on shared knowledge and pragmatic conventions, some instances of code-mixing and code-switching in online communication go beyond a simple reflection of spoken conversational patterns. What the language mixing instances reported in these studies share are their implicitly or explicitly meta-linguistic character and their occurrence in discourse that focuses on key identity issues of a group or community. The paper concludes that the study of codeswitching in online communication primarily in terms of its apparent "authenticity" or correspondence to spoken conversational code-switching may be limiting, and that important insights will be gained by theorising the written digital mode not as a limitation, but as a new set of conditions for the deployment of multilingual resources in discourse.

\section{Methodology}

The data used for this study were drawn from the Nigerian Online Community page on Facebook. Interactants on this platform were purposively selected. The data were gathered for four months, from April to July 2012. The period was chosen to allow room for wider coverage and objectivity. The data were analyzed using qualitative method.

\section{Data Presentation and Analysis}

Distinctive features of code-switching in the Nigerian Online Community page on Facebook are presented and discussed below. These features are simplified lexicon and sentences, tolerance of surface errors, non-adherence to the use of tones/diacritics and inconsistency in spellings/words.

\section{Simplified Lexicon and Sentences}

Simplified lexicon and sentences are some of the features of asynchronous mode of computer-mediated communication (CMC). The posters on the FACEBOOK forums use languages in a loose and free manner. The linguistic liberty and freedom enjoyed on the forums allow the posters to code-switch in a simplified lexicon. They do this in a very creative and innovative way. For instance;

Faloye Olawumi E gbagbe oshi mimiko is deir Godfather so don't deer him oder partys ar bushit iroko tiwole joo ipadabo ti sure jujuju...

June 20 at 8:29am.

'Forget it, Mimiko is their god father. Do not dare him. Other parties are bullshit, Iroko has won and second term is too sure.'

(Text 1)

In the text above, the simplified words are in bold fonts. It is glaring in the words above the ease at which the posters simplify their lexicon. 'deir' (their), 'deer' (dare) 'oder' (other) 'partys' (parties) 'ar' (are) 'bushit' (bullshit) are used in a special way in the post above which is one of the linguistic features in the FACEBOOK forums. The meanings of those words are left with the addressee or other posters to guess. The role of context cannot be ruled out here. Context is the only available option to aid the posters' full grasp of what is written.

If the meanings of the words are studied in isolation, it will not make any sense. For instance; the words 'deir' and 'oder' do not even exist in the lexicon of the English language, it is merely the creativity of the poster. There is no end to the generation of these words. The word 'deer' does not refer to animal in that context, rather it means to challenge. Also, the word 'oder' does not refer to any other thing than the English word 'other'. The posters are not saying rubbish as some people would think, rather, they have chosen to adopt simplified lexicon to express themselves on the forums. There is a mutual understanding among the posters. The context must be invoked to guess what the text is talking about.

Murray (1990:43-44) opines that computer science professionals delete subject pronouns, determiners and use mixed case in synchronous computer-mediated communication in work place environment. Murray's view is relevant to what obtains in the data for this study. Similar cases of this are found in the data when posters switch from English to Yoruba and vice-versa. There are numerous instances of abbreviated words. This feature is not restricted to only FACEBOOK forums but it is a common feature of $\mathrm{CMC}$. This might be as a result of time constraint or effort at minimizing typing stress. However, the posters style of abbreviation on these FACEBOOK forums is unique and extra-ordinary. For instance;

Jimoh Shola No 2nd term 4 iroko again bcs mimiko already said it s a TABOO 2 ondo state 4 2nd term pls hep me tel ur bro dat d time hs come nw. Igba odun o nbo wa dola, ds $\mathbf{s} \mathbf{d}$ time w'r talkin abt ABRAHAM S OUR MAN.

June 20 at 5:53pm

'There is no second term for Iroko because Mimiko has already said that second term in Ondo State is a taboo. Please tell your brother that the time has come now. Two hundred years are coming to be tomorrow. This is the time we are talking. Abraham is our man'.

In the text above, there are instances of mixed cases. The reason why the poster chose to use upper case for some words instead of the lower case is probably to draw attention to the words and to show their effect on the thread. Since the forum is a political one, the poster tried to object to the second term for the serving governor and advocated for his own candidate, that is 'Abraham'. Also, the word 'taboo' is typed in capital letters to describe the second term ambition of the governor as a taboo. So, the use of the upper case by the poster is meant to show emphasis and convey a special message.

Also, there is no standard for abbreviation of words in the forums. Every word in the posts has its own special and unique abbreviation. For instance, the words in the bold 
font above like hep, tel, ur, bro, dat, d, hs, nw, ds, s d, w'r, talkin, abt, etc can further be abbreviated in another special and unique way. 'Dat' can turn to dt, w'r - w re, talkin talkn/tolkin, bro- broda/bros, ds- ths, hep- hp, ur-yr/r and so on. It is only context that can clarify any ambiguity.

\section{Non-Adherence to the Use of Tones/Diacritics}

The posters do not adhere to the use of diacritical marks/tones in the Yoruba language. They don't use the diacritics to indicate a proper pronunciation of the words. Some of these words may have more than one meaning if the diacritics are not put on them. Some of the words are 'eru', 'awon', 'ode' etc. For instance;

Adegoke Johnson Adeyoju Even in london where dey compare asiwaju \& obasanjo 2geda, JAGABAN WIN....awon ode kan wa fi oba we eru lasanlasn.

'Even in London where they compared Asiwaju and Obasanjo together, Jagaban won. Some fools now compare king with ordinary slave'.

(Text 3)

In the above text, the word 'ole' could mean a thief or a lazy person. Also, 'eru' could mean fear, slave or luggage. The word 'ode' could also mean hunter, party or a stupid person. The proper pronunciation and meaning of these words could be achieved through the proper placement of diacritics/tones. However, context can still be resorted to, to decipher the meanings of these words.

\section{Inconsistencies of Spellings and Words}

There are so many inconsistencies of spellings and words in the process of switching codes from English to Yoruba and vice-versa by the users on the forums. For instance:

Adegoke Johnson Adeyoju@adepoju oti poju joor..........tell dem mke den hear

'@Adepoju, you are too much...tell them, let them hear'.

Akinlami Geyrils Alaba @Odidi...fly ke?nibo nbe?...this is a drunk eagle; he can't just fly lai lai......gbasibeee lolese, gbasibee lonigboro!!!

July 22 at :43pm

'@Odidi, you mean fly? Where?... 'an eagle that is drunk can never fly'. 'Gbasibe' is the person that can do it. 'Gbasibe' is the talk of the town'.

Segun Odidi@Geyrils, but its dis same Gbasibe dat said Omo ti o mowe lon ka kilasi kan leemeji, o daju wipe gbasibe ti fail niyen ooooo abi?

July 22 at 9:47pm

'@Geyrils, it is this same 'Gbasibe' that said it was a dull child that repeats a class twice. It is certain now that 'Gbasibe' has failed, isn't it?'

(Text 4)
In the examples above, we cannot reconcile the use of 'joo' with 'joor', and 'gbasibe', 'gbasibee' and 'gbasibeee'. The posters are not consistent with the usage of words and spellings. The standard usage is 'joo', and 'gba sibe'. This is also true of the English words 'make' (mke) and 'them' (dem). This is the liberty the posters take with the use of language on the forums. However, the context of use could help to decipher the meaning of the message.

\section{Unnecessary Lengthening of Letters}

Posters on the forums deliberately lengthen letters of words when they code-switch to Yoruba. One reason that may be adduced to this is to make the word prominent in the expression. In other words, they use this to lay emphasis on the word so that its importance and significance will be foregrounded. It is also being used to mock or ridicule the co-posters. For instance;

Bakinwa Modupe No problem. ooooooole, o lo ju kokoro

Yesterday at 10:39am

There is no problem. Thief, greedy person

The italicized word 'ole' is used to lampoon another poster on the forum. The letter lengthening is aimed at emphasizing the point of mocking the other poster as a thief. The word 'ole' (thief) in the above expression as being used by the poster does not necessarily mean a thief in the real sense of it; rather it is just a way of deriding other posters. Context as proposed by Halliday (1991) has a role to play here to really know the exact function of the utterance in the context of its usage. He describes context of situation in terms of three main features: field of discourse, tenor of discourse, and mode of discourse. Thus, we look at the participants/posters, the subject matter of what they post and the means of saying them.

It is worthy of note that lengthening of letters is not restricted to Yoruba, it also exists in English. For instance:

Bonny Yele Romeo Result of forthcoming election

LP first, PDP second and ACN third. Iroko, congrat 000000000 .

June 23 at 5:09pm

'The results of the forthcoming elections; LP is first, PDP is second and ACN is third. Iroko accept my congratulations!'

(Text 6)

Furthermore, there are situations whereby lengthening of letters can occur with the use of the two languages in a single post. This might also be attitudinal. This is because the posters see lengthening of letters as a matter of attitude. It has become what they are used to in the FACEBOOK forums. Such expression is found in the data below:

Ayodele Omoyeni IROKO, no shaking! God has ordained you from heaven for this earthly selfless 
service to humanity. So carry goooooooooooo.2013, o sure jиииииииииииииииииииии.

'Iroko, there is no shaking! God has....

2013 is too sure'.

\section{Tolerance of Surface Errors}

Herring (2001) believes that although language in CMC is less standard when compared with the standard written language, only a small percentage of these less standard forms turn out to be errors. These include grammatical, spelling, punctuation and capitalization errors.

The submission of Herring (2001: 616) that only a small percentage of those errors are caused by the lack of knowledge of the standard language forms could be true. Posters know the rules of language but they just prefer the use of cyber language which is now the new trend in CMC. The phenomena of surface errors are inundated in the posts of Yoruba-English bilinguals of these forums. Some of these surface errors can be seen below:

Akinluyi Opeyemi Hnnn,yoruba people wil say,

' $n k a n n$ be' my advise is dat, $\mathrm{u}$ ar goin 2 diclear $\mathrm{d}$ fact.

Friday at 8:49am

'Yoruba people will say 'there is something'. My advice is that you will have to declare the fact'.

(Text 8)

The example above is just a good case in point, illustrating what is said above. When the poster switched from Yoruba to English, there is a word 'diclear'. From the context, this word should be 'declare'. The fact that the poster did not correct it is not that he did not realize the spelling error but such errors that are acceptable in informal communication on the Internet as long as they do not hinder understanding. The phenomenon of surface errors comes from users' intention to "economize on typing effort or express themselves creatively" (Herring 2001: 617). Also, this might also be based on pronunciation forms in Nigerian English. In relation to this is the use of 'advise' a verbal element instead of 'advice'. This is still a deliberate act of the poster since it is allowed on CMC as far as it does not alter the meaning of the post in the context of its use.

\section{Conclusion}

Internet communication is recurrently characterized by the mixing or switching of two or more languages (Danet \& Herring, 2007). The users of FACEBOOK forums selected for this study are bilinguals who have at least two or more languages in their speech repertoire. The practice of bilingualism is highly demonstrated by the posters on the forums, resulting in code-mixing and code-switching. The present study has investigated the surface features of codeswitching in the Nigerian Online Community on Facebook. The study pays special consideration to code-switching among bilingual users of English, Yoruba and Pidgin on Facebook, using the Nigerian Online Community page. The study answers the question: What are the various surface features of code-switching in Internet chatting.

\section{References}

Akindele, F. \& Adegbite, W. 2005. The sociology and politics of English in Nigeria: An introduction. Ife: OAU Press.

Androutsopoulous, J. 2001. Switching from national language to English in media discourse: Some findings from German youth-cultural media, 1 July 2009, <http:// ww w.ids - mannheim.de/prag/s p rach variation/tp/tp7/oxford-draft.pdf $>2011$. Codeswitching in computer-mediated communication. Forthc. in: S. C. Herring, D. Stein \& T. Virtanen (eds), Handbook of the pragmatics of CMC. Mouton de Gruyter.

Awonusi, V. 2004. 'Cycles of linguistic history: the development of English in Nigeria'. In Nigerian English: influence and characteristic, Dadzie, A. B. K. \& Awonusi, V. O (eds). Lagos: Concept Publications Limited, 47-48.

Cardenas-Claros, M. \& Isharyanti, N. 2009. 'Code- mixing and code-switching in Internet Chatting: between 'yes' 'ya' and 'si' a case study. The JALT CALL journal 2009: Forums, ISSN 1832-4215 Vol. 5, No 3 pages 67-68.

Danet, B. \& Herring, S. 2007. The multilingual Internet: language, culture, and communication online. Oxford, UK: Oxford University Press.

Eggins, S. (1994). An introduction to systemic functional linguistics. London: Pinter Publishers.

Elugbe O. \& Omamor A. 1991. Nigerian Pidgin: Background and prospects. Ibadan: Heineman Education Books.

Finch, G. 2000. Linguistic terms and concepts. Palgrave: Macmillan.

Finney, M. 2004. Substratal influence on the morphosyntactic properties of Krio. Linguistic discovery 2 (2), 58-83.

Georgakopoulou, A. 1997. Self-presentation and interactional alignments in e-mail discourse: The style- and code-switches of Greek messages. International Journal of Applied Linguistics 7: 141-164.

Gotzsche, H. (2009). Key ideas in linguistics and the philosophy of language. Systemic functional grammar. Eds. S. Chapman \& C Routledge. Edinburg: Edinburg University Press.

Halliday, M. 1991. 'Towards probabilistic interpretations'. Ventola, E. (ed.) Functional and systemic linguistics: approaches and uses. (TLSM55). Berlin/ New York: Mouton de Gruyter. pp.39-61.

Halliday, M. A. K. (1994).An introduction to functional grammar. 2nd Ed. London: Edward Arnold. 
Herring, S. 2001. Computer-mediated discourse. In D. Schiffrin, D. Tannen \& H. Hamilton (eds.) The handbook of discourse analysis. Masschusetts, Oxford: Blackwell, 612-634.

Holm, J. 1988. Pidgins and Creoles (volume 1). Cambridge: Cambridge University Press.

Huang, D. 2004. Code switching and language use in emails. Unpublished Ph.D thesis, The University of Melbourne, Melbourne. 2009. Language use in asynchronous computer-mediated communication in Taiwan. Australian review of applied linguistics, volume 32, number 2, Monash University ePress.
Murray, D. 1990. CMC: a report on the nature and evolution of on-line e-message. English Today 23: 42-46.

Myers-Scotton, C. 1979. Code-switching as a 'safe choice' in choosing a lingua franca. In William McCormack \& S. Wurm (eds.), language and society. The Hauge: Mouton pp. 71-88.

Sapir, E. 1929. 'The status of linguistics as a science' in Mandelbaum, D. (ed). Selected writings of Edwards Sapir, California: California University Press.

Wardhaugh, R. 1998. An introduction to sociolinguistics. Massachusetts: Blackwell Publishers. 